\title{
Studies About the Hydration of Hybrid "Alkaline-Belite" Cement
}

\author{
M. J. Sánchez-Herrero, Ana Fernández-Jiménez* and A. Palomo \\ Department of Materials, Eduardo Torroja Institute (CSIC), Madrid, Spain
}

The mechanical performance of a hybrid cement containing 48\% fly ash, $48 \%$ mineralized belite clinker, $1.5 \%$ gypsum and $2.5 \% \mathrm{Na}_{2} \mathrm{SO}_{4}$ was analyzed and the hydration products were identified. The findings showed that the newly designed cement met European standard EN 197-1 compositional, mechanical and setting time requirements (cement type IVB). The hydration products forming in this blended "alkaline-belite" cement (as it was determined through XRD, ${ }^{29} \mathrm{Si}$ and ${ }^{27} \mathrm{Al}$ MAS NMR and electron microscopy) consisted in a mix of cementitious gels: C-(A)-S-H and N-(C)-A-S-H, which interacted and over time evolved toward the latter with no detriment to the mechanical strength developed by the cement.

Keywords: hybrid cement, belitic cement, alkaline cement, NMR-MAS, XRD

\section{OPEN ACCESS}

Edited by:

Miroslav Komljenovic, University of Belgrade, Serbia

Reviewed by: Yiannis Pontikes, KU Leuven, Belgium Ionut Ovidiu Toma,

Gheorghe Asachi Technical University of laşi, Romania

${ }^{*}$ Correspondence:

Ana Fernández-Jiménez anafj@ietcc.csic.es

Specialty section:

This article was submitted to Structural Materials, a section of the journal Frontiers in Materials

Received: 22 January 2019 Accepted: 01 April 2019 Published: 18 April 2019

Citation:

Sánchez-Herrero MJ

Fernández-Jiménez $A$ and Palomo $A$ (2019) Studies About the Hydration of Hybrid "Alkaline-Belite" Cement.

Front. Mater. 6:66.

doi: 10.3389/fmats.2019.00066

\section{INTRODUCTION}

The $\mathrm{CO}_{2}$ emissions due to Portland cement production are environmentally problematic mainly due to the very high volume of demand for cement in view of concrete needs in the world. Actually, Portland cement production is continuously increasing at global level and there exists a general agreement to consider Portland cement responsible of $7-8 \%$ of the total emissions of carbon dioxide in the world (Scrivener et al., 2018a). The use of alternative fuel, the addition of minerals to Portland cement, the inclusion of mineralizers and fluxes in the raw mix, along with the development of alternative binders, are some of the sustainable solutions envisaged today by the cement industry and the scientific community (Lothenbach et al., 2011; Zhang et al., 2012). Belite (Chatterjee, 1996; García-Díaz et al., 2011; Staněk and Sulovský, 2015), alkaline and hybrid alkaline cements (Deschner et al., 2012; García Lodeiro et al., 2013, 2016) are among the binders studied as alternatives to the traditional Portland cement.

The use of supplementary cementitious materials (SCMs, pozzolans, fly ash, blast furnace slag, limestone, etc.) as a partial substitute of Portland cement clinker in the so-called "blended cements" (Lothenbach et al., 2011; Zhang et al., 2012; Wa et al., 2018) represents not only a feasible solution but, for sure, the most investigated one. However, due to the low hydraulic activity of the SCMs, blended cements usually show delayed setting times and low early mechanical strength development, which is actually limiting the replacement of clinker by SCMs in the cement (Lothenbach et al., 2011). Obviously, many investigations are being focused on how to improve the reactivity of these SCMs. The main choices are: (i) Mechanical activation (Knop and Peled, 2016; Liu et al., 2018) (controlling the particle size distribution); (ii) Thermal activation (Vizcaíno-Andrés et al., 2015; Scrivener et al., 2018b) (especially for calcined clays-LC3 technology-); (iii) Chemical activation (Ruiz-Santaquiteria et al., 2013; Allahverdia and Malekia Mahinroosta, 2018) ("alkaline activated cement"). It is quite probable that future will lead to us to a combination of those options above mentioned like the most effective choice.

In this context the main goal of this work is to describe and discuss part of a research project (leaded by authors of this paper) linked with the development of some different types of "Hybrid 
Alkaline Cements" (HYC). HYC are binders containing a small fraction of Portland clinker (or even blast furnace slag) as a source of calcium, a large fraction of aluminosilicate materials (from natural origin or byproducts from some industries, such as fly ashes (Deschner et al., 2012; García Lodeiro et al., 2013, 2016) as a source of Si and Al, and obviously some alkaline additive. Due to a wide compositional range and to a high technological, economical and environmental potential, HYC are the object of considerable research (Qu et al., 2016; Al-Kutti et al., 2018).

Inasmuch as the presence of alkalis in the medium affects, aluminosilicate and Portland clinker reactivity, this study undertook an in-depth analysis of calcium silicate and calcium aluminate behavior after hydration by a number of alkaline solutions of different concentrations. The findings revealed that the compressive strength of $C_{3} A, C_{3} S$ and $\beta-C_{2} S$ pastes rose in the presence of alkaline additives (Sánchez-Herrero et al., 2012, 2016). Most significantly, given the low initial reactivity of $\beta-C_{2} S$ under normal hydration conditions, the presence of such alkaline

TABLE 1 | Chemical (wt\% of oxides) and mineralogical composition of the materials.

\begin{tabular}{lcccllc}
\hline \multicolumn{3}{c}{$\begin{array}{c}\text { Chemical composition } \\
\text { (wt\% of oxides) }\end{array}$} & & & Mineralogical composition (\%) \\
\cline { 1 - 2 } Oxide & Ash & Clinker & Gypsum & Phase & Hybrid cement \\
\hline $\mathrm{SiO}_{2}$ & 51.4 & 21.8 & 19.1 & $\mathrm{SiO}_{2}$ & 6.3 \\
$\mathrm{Al}_{2} \mathrm{O}_{3}$ & 25.8 & 5.9 & 7.6 & & $\mathrm{Mullite}_{n}$ & 4.8 \\
$\mathrm{Fe}_{2} \mathrm{O}_{3}$ & 5.7 & 2.6 & 2.7 & $\mathrm{C}_{3} \mathrm{~S}$ & 11.4 \\
$\mathrm{CaO}$ & 4.6 & 60.5 & 20.5 & $\beta-\mathrm{C}_{2} \mathrm{~S}$ & 19.3 \\
$\mathrm{MgO}$ & 1.5 & 2.7 & 2.8 & $\mathrm{C}_{3} \mathrm{~A}$ & 1.3 \\
$\mathrm{SO}_{3}$ & 0.8 & 3.8 & 25.5 & $\mathrm{C}_{4} \mathrm{AF}$ & 3.8 \\
$\mathrm{~K}_{2} \mathrm{O}$ & 1.7 & 1.7 & 1.5 & $\mathrm{C}_{11} \mathrm{~A}_{7} \cdot \mathrm{CaF}_{2}$ & 1.1 \\
$\mathrm{Lol}$ & $6.2^{(1)}$ & 0.0 & $19.7(2)$ & $\mathrm{CaSO}_{4} \cdot 2 \mathrm{H}_{2} \mathrm{O}$ & 1.2 \\
Other & 2.3 & 1.0 & 0.6 & $\mathrm{Na}_{2} \mathrm{SO}_{4}$ & 2.2 \\
Total & 100 & 100 & 100 & $\mathrm{Amorphous}_{4}$ & 48
\end{tabular}

additives hastened its hydration, affecting setting and hardening times substantially.

A mineralized belite clinker (with a belite content of over $50 \%$ ) was first synthesized in the laboratory. In light of its good performance and given that the clinkerization temperature could be lowered considerably in the presence of the fluxing pair formed by "CaSO 4 and $\mathrm{CaF}_{2}$," the clinker was subsequently manufactured on an industrial scale with satisfactory results. The industrial belite clinker was then blended with fly ash, gypsum (the setting regulator) and $\mathrm{Na}_{2} \mathrm{SO}_{4}$ as an alkaline additive to produce the "alkaline-belite" cement (some type of HYC).

This paper consequently describes and discusses the main singular characteristics (mechanical behavior and microstructural development) of this "alkaline-belite" cement initially formulated in the laboratory and successfully produced on an industrial scale. This advance in the design of an alkalinebelitic binder (reasonably sustainable one) was achieved due to a close collaboration between the scientific and industrial communities who simultaneously deployed some different technologies (different fields of knowledge within the "cement science") in order to produce and study the new "alkalinebelite" hybrid cement which was the object of the project. The different fields of knowledge simultaneously applied in this project were: the use of mineralizers and fluxes to produce low energy clinkers (Blanco-Varela et al., 1997; García-Díaz et al., 2011), the use of industrial by-products to generate blended cements with a low clinker factor (Deschner et al., 2012; García Lodeiro et al., 2013); and the use of affordable and innocuous natural mineral salts (alkaline additives with a minimal environmental impact) to stimulate the alkaline activation processes (García Lodeiro et al., 2016).

\section{EXPERIMENTAL}

\section{Materials}

A mineralized belite clinker produced in an industrial rotary kiln, a fly ash, gypsum (all supplied by the manufacturer) and 99.9\% pure sodium sulfate (MERCK laboratory reagent) were

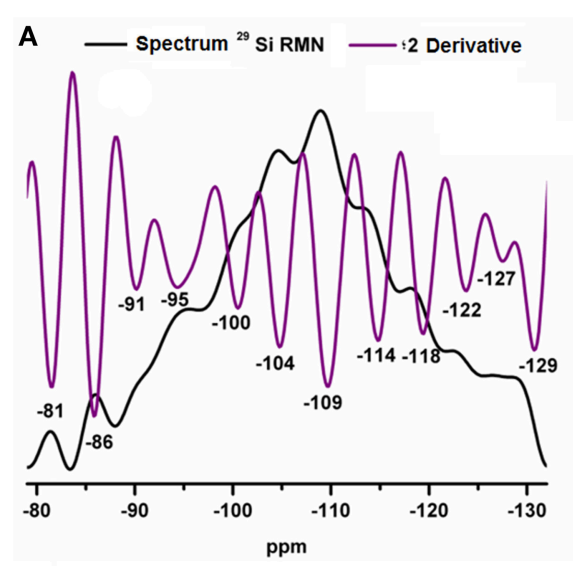

B

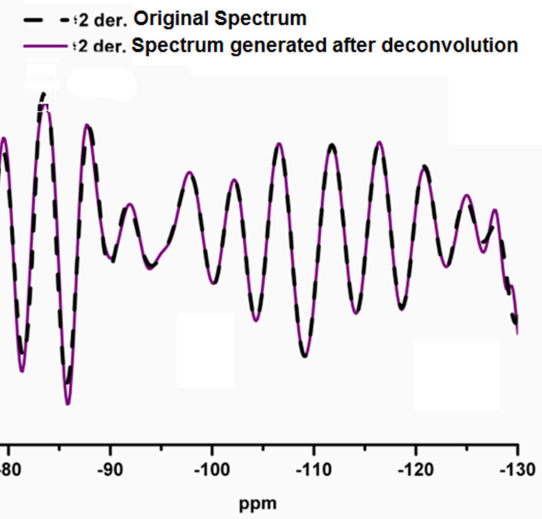

FIGURE 1 | (A) ${ }^{29}$ Si MAS NMR spectrum for fly ash and second derivative of the spectrum; (B) second derivatives of the original ${ }^{29}$ Si MAS NMR spectrum for fly ash and of the envelope generated by deconvolution. 

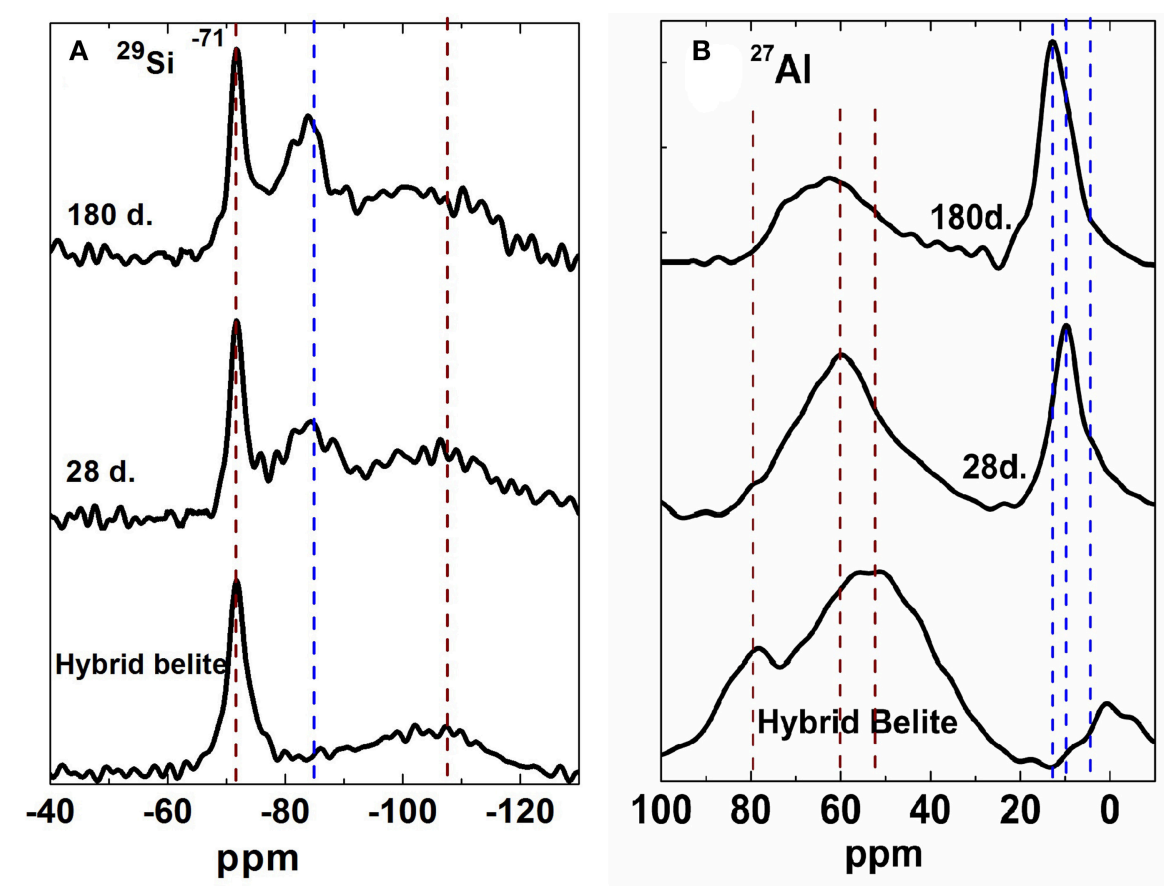

FIGURE 3 | (A) ${ }^{29}$ Si MAS NMR and (B) ${ }^{27}$ Al MAS NMR spectra for anhydrous hybrid alkaline-belite cement and $28 \mathrm{~d}$ and $180 \mathrm{~d}$ hydrated pastes.

The ${ }^{29} \mathrm{Si}$ and ${ }^{27} \mathrm{Al}$ nuclei were scanned on a Bruker MSL 400 NMR spectrometer. The conditions for ${ }^{29} \mathrm{Si}$ were: resonance frequency, $79.5 \mathrm{MHz}$; spinning rate $10 \mathrm{kHz}$; pulse sequence, single pulse $(5 \mu \mathrm{s})$; recycle delay, $10 \mathrm{~s}$; number of transients, 4912; internal standard for measuring chemical shift (in ppm), tetramethylsilane (TMS). For ${ }^{27} \mathrm{Al}$ they were: resonance frequency, $104.3 \mathrm{MHz}$; spinning rate, $10 \mathrm{kHz}$; recycle delay, $5 \mathrm{~s}$; pulse sequence, single pulse $(2 \mu \mathrm{s})$; number of transients, 400; internal standard for chemical shift measurements (in ppm), $\mathrm{Al}\left(\mathrm{H}_{2} \mathrm{O}\right)_{6}^{3+}$.

The ${ }^{29} \mathrm{Si}$ NMR spectra were deconvoluted in order to determine the number and position of the signals analyzed. The second derivative criterion was used (Kucherov and Kochubei, 1983; Pérez et al., 2014). This procedure is highly useful when analyzing spectra with wide, poorly defined signals, inasmuch as it resolves closely juxtaposed resonant frequencies and determines the exact position of each. In this particular case two software applications (OriginPro 9 and MestReNova) were used with the objective of avoiding practical mistakes. The ${ }^{29}$ Si MAS NMR signals exhibited a Lorentzian/Gaussian (L/G) ratio of 0.5 (independent on the software). First derivative analysis reveals the presence of peaks that appear as shoulders or weak signals on the original spectrum, whilst the second derivative furnishes more precise information in the form of minima, the value of which concurs with the peak on the main signal. The number of points taken into account during the analysis (in the zone of the spectrum between -60 and $-130 \mathrm{ppm}$ ) was 450 approximately. Figure 1 is an example of ${ }^{29} \mathrm{Si}$ MAS NMR spectra of our fly ash. This spectrum at Figure $\mathbf{1}$ is an example of analysis by following the already explained procedure.
Finally some samples were vacuum dried and carbon-coated for examination under a HITACHI S-4800 (Tokyo, Japan) scanning electron microscope fitted with a Bruker energy dispersive spectroscope to confirm the working hypotheses. For BSEM analysis, the samples were embedded in epoxy resin, cut and polished with ethanol prior to vacuum drying and carbon coating.

\section{RESULTS AND DISCUSSION}

\section{Material Properties}

Material compressive strength and setting time data are given in Table 2. The mechanical strength development of mortars $(4 \times$ $4 \times 16 \mathrm{~cm}^{3}$ prismatic) was $10.8 \mathrm{MPa}$ at 2 days $40.0 \mathrm{MPa}$ at 28 days, and $51.9 \mathrm{MPa}$ at 180 days. The initial setting time was $t_{\mathrm{i}}$ $=83 \mathrm{~m}$. and the final $t_{\mathrm{F}}=193 \mathrm{~m}$; the belitic hybrid cement met European standard requirements for 32.5 type cement (EN 1971 Cement-Part 1: Composition, specifications and conformity criteria for common cement).

As noted, this cement contained $48 \%$ mineralized belite clinker, which is characterized by low early age reactivity (Taylor, 1997). According to these findings, the constituents of the alkaline-belite cement generated synergies during hydration that contributed favorably to strength development. The heat of hydration released by the belite clinker fraction, in conjunction with the presence of the $\mathrm{Na}_{2} \mathrm{SO}_{4}$, sufficed to alkali-activate the fly ash, affording the system good initial mechanical behavior. Furthermore, as noted in prior studies (Sánchez-Herrero et al., 2017), the data appeared to indicate that the presence of the alkaline additive stimulated greater strength development in the 


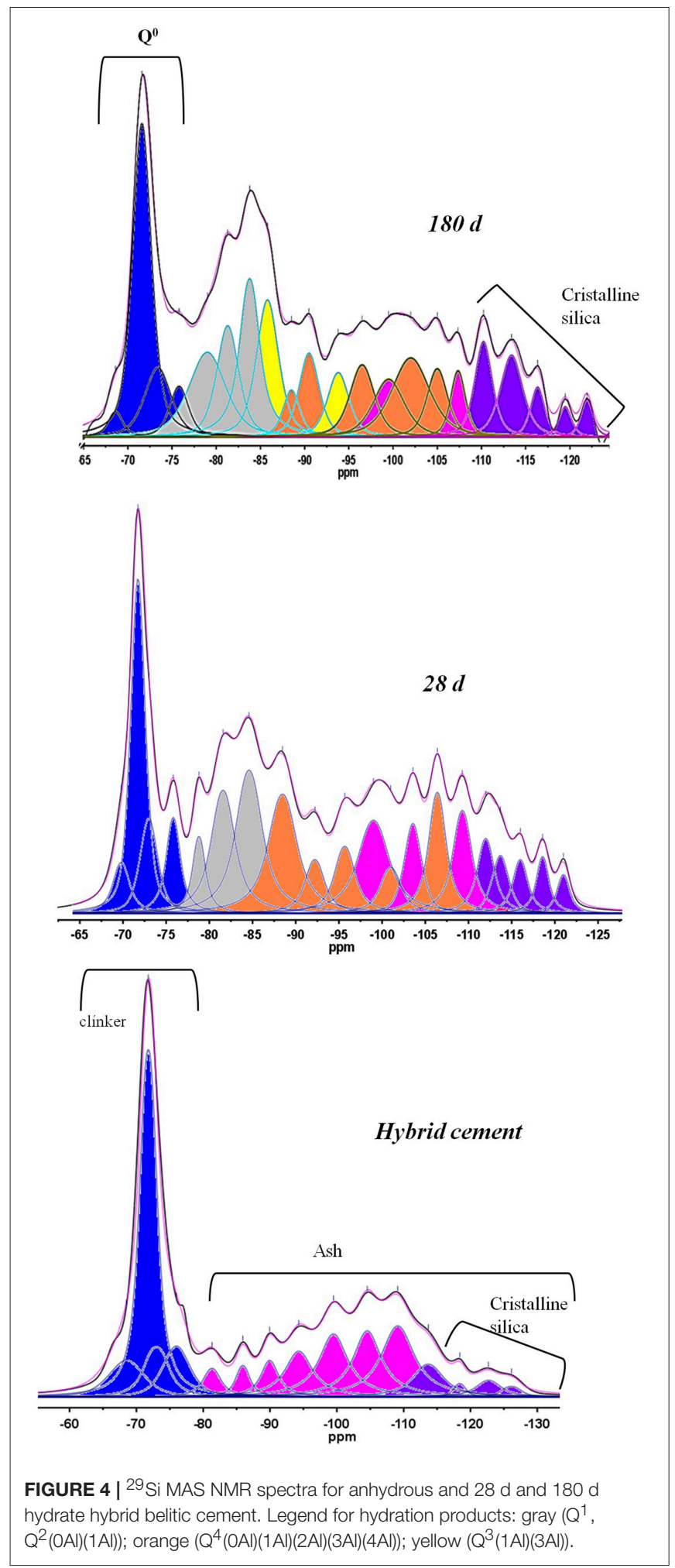

calcium silicates and aluminates present in the clinker than observed during normal water-based hydration.

In previous papers (Donatello et al., 2013) authors have already demonstrated that hybrid cements behave quite well
TABLE 3 | Chemical shifts (ppm) recorded after deconvolution of ${ }^{29}$ Si MAS NMR spectra for hybrid cement and $28 \mathrm{~d}$ and $180 \mathrm{~d}$ cement pastes.

\begin{tabular}{|c|c|c|c|c|c|c|}
\hline \multirow[t]{2}{*}{ Attributed to } & \multicolumn{2}{|c|}{ Anhydrous } & \multicolumn{2}{|c|}{$28 \mathrm{~d}$} & \multicolumn{2}{|c|}{$180 \mathrm{~d}$} \\
\hline & $\delta$ (ppm) & Area (\%) & $\delta($ ppm) & Area (\%) & $\delta$ (ppm) & Area (\%) \\
\hline $\mathrm{Q}^{0} \mathrm{C}_{3} \mathrm{~S}$ & -68.5 & 5.6 & -69.8 & 2.2 & -68.6 & 1.04 \\
\hline $\mathrm{Q}^{0} \mathrm{C}_{2} \mathrm{~S}$ & -71.7 & 27.5 & -71.4 & 14.0 & -71.6 & 15.0 \\
\hline $\mathrm{Q}^{0} \mathrm{C}_{3} \mathrm{~S}$ & -73.0 & 5.6 & -73.0 & 5.1 & -73.0 & 4.7 \\
\hline $\mathrm{Q}^{0} \mathrm{C}_{3} \mathrm{~S}$ & -76.0 & 6.0 & -75.8 & 3.0 & -75.8 & 2.4 \\
\hline$Q^{1} \mathrm{C}-\mathrm{S}-\mathrm{H}$ & - & - & -78.8 & 3.0 & -79.0 & 8.0 \\
\hline Ash/Q ${ }^{2}(1 \mathrm{Al})$ & -81.3 & 2.5 & -81.6 & 8.0 & -81.3 & 6.2 \\
\hline $\mathrm{Q}^{2}(\mathrm{OAl})$ & - & - & -84.6 & 10.0 & -83.8 & 9.0 \\
\hline Ash $/ Q^{3}(3 A l)$ & -85.9 & 2.2 & - & - & -85.8 & 7.7 \\
\hline Ash/Q ${ }^{4}(4 \mathrm{Al})$ & -89.9 & 3.3 & -88.5 & 8.7 & -88.5 & 2.0 \\
\hline$Q^{4}(3 \mathrm{Al})$ & - & - & -92.2 & 3.2 & -90.5 & 4.3 \\
\hline Ash $/ Q^{3}(1 \mathrm{Al})$ & -94.3 & 6.6 & - & - & -93.8 & 3.5 \\
\hline $\mathrm{Q}^{4}(2 \mathrm{Al})$ & - & - & -95.7 & 4.4 & -96.5 & 4.5 \\
\hline Ash $/ Q^{4}(\mathrm{mAl})$ & -99.4 & 9.6 & -99.0 & 8.3 & -99.5 & 4.5 \\
\hline $\mathrm{Q}^{4}(1 \mathrm{Al})$ & - & - & -101.0 & 1.4 & -102.0 & 7.1 \\
\hline Ash $/ Q^{4}(\mathrm{mAl})$ & -104.5 & 9.9 & -103.6 & 5.0 & - & - \\
\hline $\mathrm{Q}^{4}(\mathrm{OAl})$ & - & - & -106.4 & 5.3 & -105.0 & 3.5 \\
\hline \multirow[t]{2}{*}{$\mathrm{Ash} / \mathrm{Q}^{4}(\mathrm{mAl})$} & -109.1 & 12.1 & -109.3 & 5.4 & -107.3 & 2.4 \\
\hline & - & - & -112.0 & 3.7 & -110.2 & 4.3 \\
\hline \multirow[t]{2}{*}{ Crystalline silica } & -113.6 & 5.1 & -113.7 & 2.8 & -113.0 & 4.7 \\
\hline & - & - & -116.0 & 1.8 & -116.3 & 1.8 \\
\hline Crystalline silica & -118.4 & 0.7 & -118.6 & 2.1 & -119.5 & 1.0 \\
\hline Crystalline silica & -122.7 & 2.1 & -121.0 & 1.85 & -121.5 & 1.1 \\
\hline Crystalline silica & -126.1 & 0.9 & - & - & - & - \\
\hline
\end{tabular}

when located in aggressive environmental conditions (sulfates, marine, acidic, etc.). Additionally, they do not undergo the ASR since alkalies are consumed in the reaction of activation of fly ashes (Malvar and Lenke, 2006).

\section{Reaction Products}

The XRD patterns for the anhydrous hybrid cement and the $2 \mathrm{~d}$, 7 d, 28 d, and 180 d hydrated pastes are reproduced in Figure 2.

All the diffractograms exhibited a hump associated with the vitreous fraction of the fly ash and the existence of a cementitious gel precipitating during hydration. The intensity of the diffraction lines for belite was observed to decline steadily with hydration time.

All the pastes generated diffraction lines attributed to quartz and calcite. Ettringite was identified in the $2 \mathrm{~d}$ and $7 \mathrm{~d}$ patterns, whereas the $28 \mathrm{~d}$ and $180 \mathrm{~d}$ materials contained vaterite. No signals associated with portlandite were identified at any of the ages studied.

Figure 3 contains the ${ }^{29} \mathrm{Si}$ MAS NMR and ${ }^{27} \mathrm{Al}$ MAS NMR spectra for the anhydrous cement and the $28 \mathrm{~d}$ and $180 \mathrm{~d}$ pastes. Some of the signals on the hydrated paste spectra were absent on the scan for the anhydrous cement. These wide, poorly defined signals may be indicative of the presence of a mix of several components.

The ${ }^{29} \mathrm{Si}$ MAS NMR deconvoluted spectra for the hybrid cement and its hydrated pastes are reproduced in Figure 4, whilst 
Table 3 give the chemical shifts and area for each signal identified on the spectra analyzed.

The ${ }^{29}$ Si MAS NMR spectrum for the anhydrous cement exhibited a narrow signal in the clinker fraction at around -71 ppm attributed to belite, and a series of wider signals associated with the $\mathrm{C}_{2} \mathrm{~S}$ and $\mathrm{C}_{3} \mathrm{~S} \mathrm{Q}^{0}$ units in alite (Sánchez-Herrero et al., $2016,2017)$. The area of the spectrum between $-81 \mathrm{ppm}$ and $-120 /-130 \mathrm{ppm}$ was associated with the fly ash fraction in the cement. Deconvolution of this area of the spectrum revealed the presence of several components. The signals between $-85 \mathrm{ppm}$ and $-108 \mathrm{ppm}$ in the anhydrous cement, concurrent with the presence of the ash, were attributed to $\mathrm{Q}^{4}(\mathrm{mAl})$ units (Figure 4 and Table 3) for, as these signals tended to disappear in the $28 \mathrm{~d}$ and $180 \mathrm{~d}$ spectra, they were associated with the vitreous phase in the fly ash (Engelhardth and Michael, 1987; Palomo et al., 2004). The signals at (absolute) values higher than -109 ppm, however, remained practically unchanged during cement hydration and were therefore associated with $\mathrm{Q}^{4}(0 \mathrm{Al})$ units in the various crystalline forms of silica (Engelhardth and Michael, 1987). Mullite, in turn, a crystalline phase detected in this material through $\mathrm{XRD}$, generated resonance frequencies at -86 ppm, -91 ppm, and -95 ppm (Merwin et al., 1991). The $\mathrm{Q}^{0}$ and $\mathrm{Q}^{4}(\mathrm{mAl})$ units, respectively associated with the unreacted clinker and fly ash fractions, declined in intensity in the $28 \mathrm{~d}$ and $180 \mathrm{~d}$ pastes (García Lodeiro et al., 2013, 2016).

Attribution of the new signals appearing in the $28 \mathrm{~d}$ and $180 \mathrm{~d}$ pastes was not straightforward, for different units in the cementitious gel may overlap. In such complex systems, a single signal may be assigned to different units of the gel or gels precipitating during the reaction. The signal at $-85 \mathrm{ppm}$ for instance, may be attributed to a $\mathrm{Q}^{2}$ unit in a C-S-H gel (Skibsted and Andersen, 2013), a $\mathrm{Q}^{3}(3 \mathrm{Al})$ unit in a C-A-S-H gel (Puertas et al., 2011; Myers et al., 2015) or a $\mathrm{Q}^{4}(4 \mathrm{Al})$ unit in an N-A-S-H gel (García-Lodeiro et al., 2010, 2011). In this study, attribution was based on the literature as well as the findings of other techniques discussed below ( ${ }^{27} \mathrm{Al}$ MAS NMR and BSEM/EDX).

Further to those criteria, the signals at $-78.8 /-79.0 \mathrm{ppm}$ were associated with $\mathrm{Q}^{1}$ units in C-S-H gel. Similarly, the signals at $-81.6 /-81.3 \mathrm{ppm}$ and $-84.6 /-83.8 \mathrm{ppm}$ were attributed to $\mathrm{Q}^{2}(1 \mathrm{Al})$ and $\mathrm{Q}^{2}(0 \mathrm{Al})$ units in C-(A)-S-H-like gels. C-S-H gel is the main reaction product that precipitates during ordinary Portland cement hydration. The uptake of aluminum in bridging tetrahedral positions in the $\mathrm{C}-\mathrm{S}-\mathrm{H}$ gel structure gives rise to $\mathrm{Q}^{2}(1 \mathrm{Al})$ units, favoring the formation of C-(A)-S-H gels. Both gels precipitated during hydration of the mineralized belite clinker fraction of the cement.

The gels that form in cementitious systems with a very low calcium content (such as in the alkaline activation of fly ash) are alkaline aluminosilicate hydrates (N-A-S-H gels) (FernándezJiménez et al., 2006). Such gels, which have a three-dimensional structure consisting in $\mathrm{Q}^{4}(\mathrm{mAl})$ units, constitute the main hydration product of fly ash alkaline activation. Further to that criterion, the signals located at around $-88.5 \mathrm{ppm},-92.2 \mathrm{ppm}$, -95.7 ppm, $-101.0 \mathrm{ppm}$, and $-106.4 \mathrm{ppm}$ on the $28 \mathrm{~d}$ and $180 \mathrm{~d}$ hybrid spectra would be respectively associated with the $\mathrm{Q}^{4}(4 \mathrm{Al})$, $\mathrm{Q}^{4}(3 \mathrm{Al}), \mathrm{Q}^{4}(2 \mathrm{Al}), \mathrm{Q}^{4}(1 \mathrm{Al})$, and $\mathrm{Q}^{4}(04 \mathrm{Al})$ units in a N-A-S-H gel (Engelhardth and Michael, 1987; Fernández-Jiménez et al., 2006).

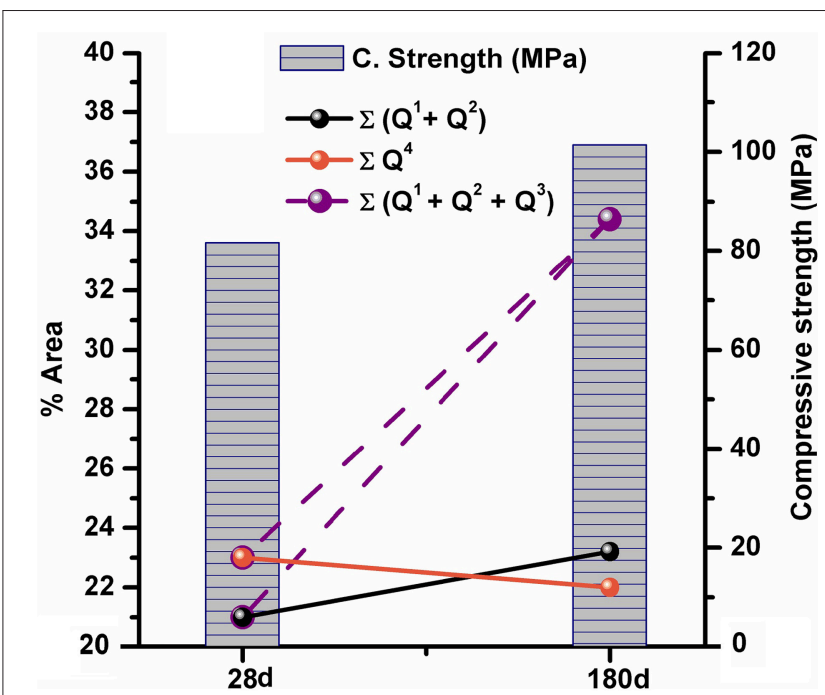

FIGURE 5 | Total areas of $Q^{1}, Q^{2}, Q^{3}$, and $Q^{4}$ units on the $28 \mathrm{~d}$ and $180 \mathrm{~d}$ ${ }^{29} \mathrm{Si}$ MAS NMR spectra and compressive strength of $3 \times 3 \times 3 \mathrm{~cm}$ paste specimens.

In these complex systems, however, the presence of calcium in the medium around the N-A-S-H gels may induce partial substitution of calcium for sodium, prompting the formation of $\mathrm{N}$-(C)-A-S-H-like gels (García-Lodeiro et al., 2010, 2011) and with it slight shifts in resonance frequencies. That would explain the fluctuations observed in the positions of the signals on the $28 \mathrm{~d}$ and $180 \mathrm{~d}$ spectra, in addition to the evolution toward the precipitation of an $\mathrm{N}-(\mathrm{C})-\mathrm{A}-\mathrm{S}-\mathrm{H}$-like gel.

Two new signals were detected in the $28 \mathrm{~d}$ spectra at around -93.8 and $-95.8 \mathrm{ppm}$, associated with $\mathrm{Q}^{3}(\mathrm{mAl})$ units. The presence of those signals can be explained on the grounds of the existence of phases precipitating in accordance with the following two mechanisms.

- Aluminum uptake into C-(A)-S-H gel. The presence of aluminum in a bridging tetrahedral position in the gel is known to favor sporadic connections between linear chains (Skibsted and Andersen, 2013). That induces the formation of flat (twodimensional) laminated silicates that give rise to $\mathrm{Q}^{3}(1 \mathrm{Al})$ units and signals at around -92/-94 ppm, indicative of a C-A-S-Hlike gel. Silicon replacement by aluminum generates a charge imbalance in the gel structure, however, favoring the uptake of $\mathrm{Na}^{+}$ions to restore the balance and driving the precipitation of N-(C)-A-S-H-like gels (Puertas et al., 2011; Myers et al., 2015).

- De-polymerization of N-A-S-H gel. The presence of calcium in the medium tends to destabilize N-A-S-H gel, for the Si-O-Al bonds break due to the polarizing action of the $\mathrm{Ca}^{2+}$ ions, with the formation of Si-O-Ca bonds (García-Lodeiro et al., 2010, 2011). The outcome is a decline in the percentage of $\mathrm{Q}^{4}(4 \mathrm{Al})$ and $\mathrm{Q}^{4}(3 \mathrm{Al})$ units and a rise in the presence of $\mathrm{Q}^{3}(4 \mathrm{Al})$ units. Whilst the aluminum exiting the three-dimensional structure of the N-A-S-H gel could be taken up in the C-S-H gel, it also tends to react with calcium to form secondary hydration products (García Lodeiro et al., 2016) such as AFm and 

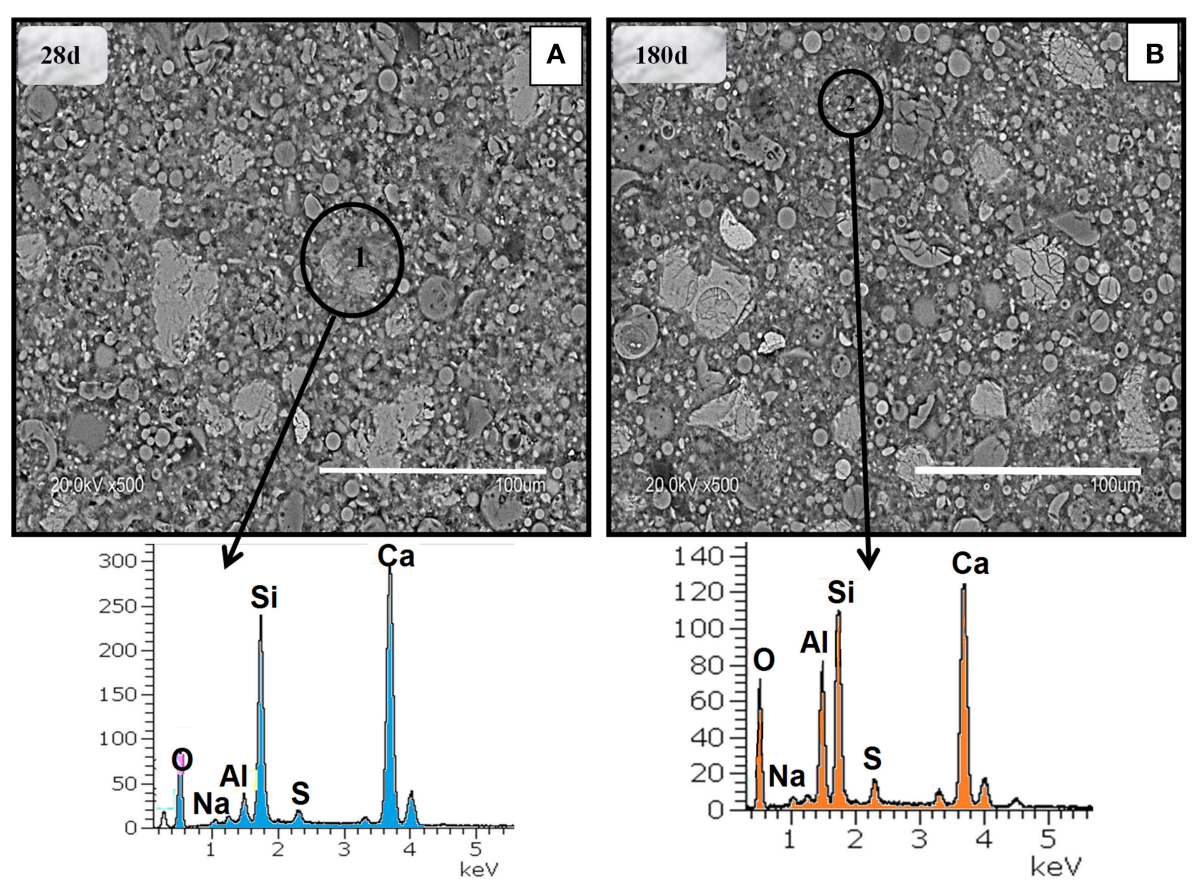

FIGURE 6 | (A) 28 d and (B) 180 d BSEM micrographs of hybrid cement pastes.

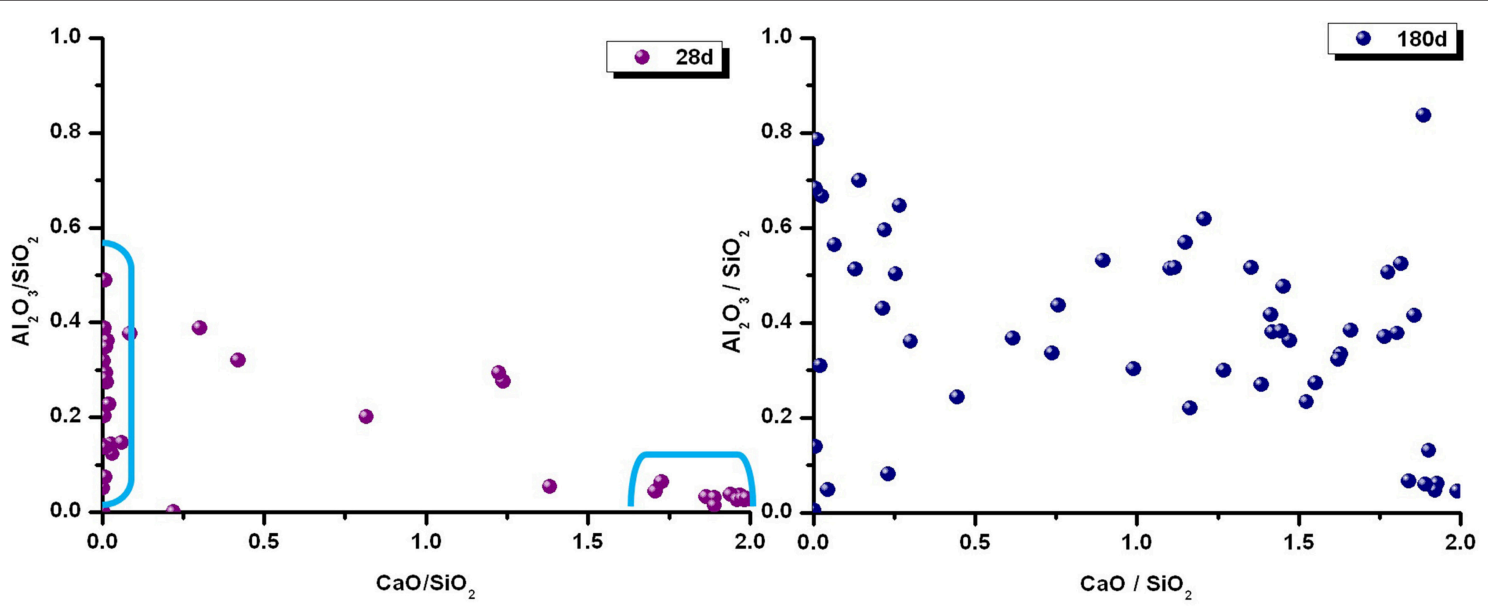

FIGURE 7 | $\mathrm{CaO} / \mathrm{SiO}_{2}$ and $\mathrm{Al}_{2} \mathrm{O}_{3} / \mathrm{SiO}_{2}$ ratios calculated from the microanalysis of $28 \mathrm{~d}$ and 180 d hybrid cement pastes.

AFt. The ${ }^{27} \mathrm{Al}$ MAS NMR spectra reproduced below in Figure 3B, support that theory, as they contain signals for scantly crystalline AFt and AFm, phases that would not be detected with XRD.

An analysis of the tetrahedral aluminum based on the ${ }^{27} \mathrm{Al}$ MAS NMR spectra for the alkaline-belite hybrid cement and its pastes (Figure 3B) revealed that the intensity of the signal at +80 ppm, associated with calcium aluminates in the clinker (Baptiste d'Espinose de Lacaillerie et al., 2008; Sánchez-Herrero et al., 2012; Skibsted and Andersen, 2013), was barely perceptible in the $28 \mathrm{~d}$ materials and disappeared almost entirely after $180 \mathrm{~d}$.
In the cement pastes, the intensity of the signal associated with the tetrahedral component of the fly ash (+52/54 ppm) declined and shifted, with the appearance of a number of signals at around $+60 \mathrm{ppm}$. The inference would be that part of the aluminum was taken up into a gel or mix of gels and surrounded by two, three or four silicon atoms, providing further evidence of complex structures comprising a mix of cementitious gels of very different characteristics. According to the literature (García-Lodeiro et al., 2010, 2011; Puertas et al., 2011; Myers et al., 2015) the $\mathrm{Al}_{\mathrm{T}}$ for $\mathrm{N}$ A-S-H gel appears close to $+57 /+60$ ppm while $\mathrm{Al}_{\mathrm{T}}$ in $\mathrm{C}-\mathrm{A}-\mathrm{S}-\mathrm{H}$ gel appears at $+65 /+68 \mathrm{ppm}$. By comparing ${ }^{27} \mathrm{Al}$ NMR spectra at 28 and 180 days, the area of the signal at around $+65 /+68$ 
ppm attributed to a C-A-S-H gel rose substantially after 180 days of hydration.

The ${ }^{27} \mathrm{Al}$ NMR spectra for the 28 and 180 days pastes (see Figure 3B) exhibited signals at around $+12 \mathrm{ppm},+9.4$ $\mathrm{ppm}$, and $+4 \mathrm{ppm}$, indicative of octahedral aluminum and respectively associated with ettringite $\left(\mathrm{C}_{6} \mathrm{~A}_{3} \mathrm{H}_{32}\right)$, calcium monosulfoaluminate $\left(\mathrm{C}_{4} \mathrm{AS} \mathrm{H}_{12}\right)$ or calcium monocarboaluminate $\left(\mathrm{C}_{4} \mathrm{~A} \hat{\mathrm{C}} \mathrm{H}_{11}\right)$ and the third aluminate hydrate (TAH) (Shimada and Francis Young, 2004; Baptiste d'Espinose de Lacaillerie et al., 2008; Sánchez-Herrero et al., 2012; Skibsted and Andersen, 2013) none of these hydration products were detected with XRD. In contrast, with its high sensitivity to ${ }^{27} \mathrm{Al}$ nuclei, MAS NMR identifies compounds difficult to detect with other techniques due to the small amounts present or their low crystallinity.

Figure 5 shows the areas attributed to the $\mathrm{Q}^{1}, \mathrm{Q}^{2}, \mathrm{Q}^{3}$, and $\mathrm{Q}^{4}$ units obtained after deconvoluting the ${ }^{29} \mathrm{Si}$ MAS NMR spectra. The sum of the areas for the $Q^{1}+Q^{2}$ units (associated with a C-(A)-S-H gel) rose in the $180 \mathrm{~d}$ materials, whilst the sum of the $\mathrm{Q}^{4}$ units, corresponding to a N-A-S-H gel, declined at that age. The appearance of $\mathrm{Q}^{3}$ units in the $180 \mathrm{~d}$ pastes denoted a rise in the total area of the $\mathrm{Q}^{1}+\mathrm{Q}^{2}+\mathrm{Q}^{3}$ units associated with C-A-S-H gel precipitation, further supporting the evolution over time of the cementitious gels that precipitate during alkaline-belite hybrid cement hydration. These chemical and nanostructural changes in the cementitious gels did not compromise mechanical strength development in either the pastes (Figure 5) or the mortars (Table 2).

These findings corroborated the analysis of the ${ }^{29} \mathrm{Si}$ MAS NMR spectra, namely that the cementitious gel precipitating during hybrid "alkaline'-belite" cement hydration was actually a mix of interacting gels that evolved over time toward a gel with characteristics reminiscent of N-(C)-A-S-H gel. The evolution of cementitious gels toward a single product implies that part of the tetrahedral aluminum released into the medium was taken up into the secondary hydration products in the form of octahedral aluminum.

Further to the above analysis of the ${ }^{29} \mathrm{Si}$ and ${ }^{27} \mathrm{Al}$ MAS NMR findings, three types of cementitious gels precipitated during hybrid "alkaline-belite" cement hydration: C-(A)-S-H, C(N)-A-S-H and N-(C)-A-S-H. That was possible due to system characteristics, determined by its $48 \%$ clinker, $48 \%$ fly ash, $1.5 \%$ gypsum, and $2.5 \% \mathrm{Na}_{2} \mathrm{SO}_{4}$ contents. These cementitious gels interacted and their characteristics evolved over time toward those of a gel similar to C-(N)-A-S-H.

The EDX microanalyses of BSEM micrographs showed that the majority elements in paste chemical composition were calcium, silicon and aluminum, although different amounts of sulfur were also identified in most (Figure 6). The microanalysis conducted at point 1 on the micrograph detected the presence of a C-S-H-like gel with small amounts of aluminum (C-(A)-S-Hlike gel), whereas the microanalysis at point 2 was indicative of the presence of a C-A-S-H-like gel (Figure 6).

The $\mathrm{CaO} / \mathrm{SiO}_{2}$ and $\mathrm{Al}_{2} \mathrm{O}_{3} / \mathrm{SiO}_{2}$ molar ratios for the two pastes shown in Figure 7 were calculated from the microanalyses of the BSEM micrographs. The $28 \mathrm{~d}$ cementitious gels were observed to precipitate primarily in two areas with very different compositional ranges. In one, low calcium N-A-S-H-like gels precipitated where some cenosphere or fly ash particle was previously located, whilst C-(A)-S-H-like gels were found in the other zones (where some particle of $\mathrm{C}_{3} \mathrm{~S}$ or $\mathrm{C}_{2} \mathrm{~S}$ was existing). The $180 \mathrm{~d}$ findings showed that the chemical composition of both types of gels evolved toward a single C-A-S-H-like gel.

In short, the BSEM/EDX findings for the $28 \mathrm{~d}$ and 180 d pastes confirmed the precipitation of different types of cementitious gels and hence the existence of a mix of gels. Due to the interaction between these gels as hydration progressed, this cementitious mix evolved toward the precipitation of a hydration product with characteristics reminiscent of C(N)-A-S-H gel. The excellent technological behavior of the belitic-alkaline hybrid cement can only be explained by this nanostructural circumstance: two different cementitious gels being formed simultaneously. The extent to which formation of caco3 might contribute to the mechanical strength development has not been analyzed in this paper but authors consider it will be quite interesting point to analyze in the future since $x r d$ seems to indicate that caco3 is increasing with time of curing.

\section{CONCLUSIONS}

The most prominent conclusions to be drawn from the present study are as follows.

- Hybrid belite-alkaline cement containing 48\% fly ash can be prepared to the mechanical strength and setting time requirements laid down in European standard EN 197-1 for IVB type cement.

- Hydration of this hybrid alkaline-belite cement favored the simultaneous precipitation of a mix of cementitious gels that varied in nature: C-(A)-S-H and N-(C)-A-S-H. These gels interacted and over time evolved toward a C-(N)-A-S-H gel, with no detriment to the mechanical strength developed by the cement.

- Technologically speaking, this cement is comparable to most Portland cements on the market today, while from the environmental perspective, its manufacture is significantly more sustainable than traditional Portland cements.

\section{AUTHOR CONTRIBUTIONS}

MJS-H conducted the experiments, data analyses and characterizations. MJS-H and AF-J drafted the manuscript. AP helped with manuscript preparation and supervised the overall research. AF-J finalized the manuscript.

\section{ACKNOWLEDGMENTS}

This research was funded by the Spanish Ministry of the Economy and Competitiveness and FEDER under research projects BIA2016-76466-R and RTC2016-4872-S. 


\section{REFERENCES}

Al-Kutti, W., Nasir, M., Azmi Megat Johari, M., Saiful Islam, A. B. M., Manda, A. A., and Blaisi, N. I. (2018). An overview and experimental study on hybrid binders containing date palm ash, fly ash, OPC and activator composites. Construct. Build. Mater. 159, 567-577. doi: 10.1016/j.conbuildmat.2017.11.017

Allahverdia, A., and Malekia Mahinroosta, M. (2018). Chemical activation of slag-blended Portland cement. J. Build. Eng. 18, 76-83. doi: 10.1016/j.jobe.2018.03.004

Baptiste d'Espinose de Lacaillerie, J., Fretigny, C., and Massiot, D. (2008). MAS NMR spectra of quadrupolar nuclei in disordered solids: the Czjzek model. J. Magnet. Reson. 192, 244-251. doi: 10.1016/j.jmr.2008.03.001

Blanco-Varela, M. T., Palomo, A., Puertas, F., and Vázquez, T. (1997). $\mathrm{CaF}_{2}$ and $\mathrm{CaSO}_{4}$ in white cement clinker production. Adv. Cem. Res. 9, 105-113. doi: 10.1680/adcr.1997.9.35.105

Chatterjee, A. K. (1996). High belite cements - present status and future technological options: part I. Cem. Concr. Res. 26, 1213-1225. doi: 10.1016/0008-8846(96)00099-3

Deschner, F., Winnefeld, F., Lothenbach, B., Seufert, S., Schwesig, P., Dittrich, S., et al. (2012). Hydration of Portland cement with high replacement by siliceous fly ash. Cem. Concr. Res. 42, 1389-1400. doi: 10.1016/j.cemconres.2012.06.009

Donatello, S., Palomo, A., and Fernández-Jiménez, A. (2013). Durability of very high volume fly ash cement pastes and mortars in aggressive solutions. Cem. Concr. Comp. 38, 12-20. doi: 10.1016/j.cemconcomp.2013.03.001

Engelhardth, G., and Michael, D. (1987). High Resolution Solid State NMR of Silicates and Zeolite, Ed. London: Wiley.

Fernández-Jiménez, A., Palomo, A., Sobrados, I., and Sanz, J. (2006). The role played by the reactive alumina content in the alkaline activation of fly ashes. Micropor. Mesop. Mater. 91 111-119. doi: 10.1016/j.micromeso.2005.11.015

García Lodeiro, I., Fernández-Jiménez, A., and Palomo, A. (2013). Variation in hybrid cements over time. alkaline activation of fly ash-portland cement blends. Cem. Concr. Res. 52, 112-122. doi: 10.1016/j.cemconres.2013.03.022

García-Díaz, I., Palomo, J. G., and Puertas, F. (2011). Belite cements obtained from ceramic wastes and the mineral pair $\mathrm{CaF}_{2} / \mathrm{CaSO}_{4}$. Cem. Concr. Compos. 33, 1063-1070. doi: 10.1016/j.cemconcomp.2011.06.003

García-Lodeiro, I., Donatello, S., Fernández-Jiménez, A., and Palomo, A. (2016). Hydration of hybrid alkaline cement containing a very large proportion of fly ash: a descriptive model. Materials 9:605. doi: 10.3390/ma9070605

García-Lodeiro, I., Fernández-Jiménez, A., Palomo, A., and MacPhee, D. E. (2010). Effect of calcium additions on N-A-S-H cementitious gels. J. Am. Ceram. Soc. 93, 1934-1940. doi: 10.1111/j.1551-2916.2010.03668.x

García-Lodeiro, I., Fernández-Jiménez, A., Palomo, A., and Macphee, D. E. (2011). Compatibility studies between N-A-S-H and C-A-S-H gels. Study in the ternary diagram $\mathrm{Na}_{2} \mathrm{O}-\mathrm{CaO}-\mathrm{Al}_{2} \mathrm{O}_{3}-\mathrm{SiO}_{2}-\mathrm{H}_{2} \mathrm{O}$. Cem. Concr. Res. 41, 923-931. doi: 10.1016/j.cemconres.2011.05.006

Knop, Y., and Peled, A. (2016). Packing density modeling of blended cement with limestone having different particle sizes. Construct. Build. Mater. 102, 44-50. doi: 10.1016/j.conbuildmat.2015.09.063

Kucherov, A. P., and Kochubei, S. M. (1983). Method for decomposition of a complex profile into elementary components using a preliminary analysis of its structure. J. Appl. Spectrosc. 38, 124-128. doi: 10.1007/BF00659868

Liu, C., Huang, R., Zhang, Y. S., Liu, Z. Y., and Zhang, M. Z. (2018). Modelling of irregular shaped cement particles and microstructural development of Portland cement. Construct. Build. Mater. 115, 362-378. doi: 10.1016/j.conbuildmat.2018.02.142

Lothenbach, B., Scrivener, K., and Hooton, R. D. (2011). Supplementary cementitious materials. Cem. Concr. Res. 41, 1244-1256. doi: 10.1016/j.cemconres.2010.12.001

Malvar, L. J., and Lenke, L. R. (2006). Efficiency of fly ash in mitigating alkali silica reaction based on chemical composition. ACI Mater. J. 103, 319-326. doi: $10.14359 / 18153$

Merwin, L. H., Sebald, A., Rager, H., and Schneider, H. (1991). ${ }^{29}$ Si and ${ }^{27}$ Al MAS NMR spectroscopy of mullite. Phys. Chem. Min. 18, 47-52.

Myers, R. J., Bernal, S. A., Gehman, J. D., van Deventer, J. S. J., and Provis, J. L. (2015). The role of Al in cross-linking of alkali-activated slag cements. J. Am. Ceram. Soc. 98, 996-1004. doi: 10.1111/jace.13360
Palomo, A., Alonso, S., and Fernández-Jiménez, A. (2004). Alkaline activation of fly ashes: NMR study of the reaction products. J. Am. Ceram. Soc. 87, 1141-1145. doi: 10.1111/j.1551-2916.2004.01141.x

Pérez, G., Guerrero, A., Gaitero, J. J., and Goñi, S. (2014). Structural characterization of C-S-H gel through an improved deconvolution analysis of NMR spectra. J. Mater. Sci. 49, 142-152. doi: 10.1007/s10853-013-7688-8

Puertas, F., Palacios, M., Manzano, H., Dolado, J. S., Rico, A., and Rodríguez, J. (2011). A model for the C-A-S-H gel formed in alkali-activated slag cements. J. Eur. Ceram. Soc. 31, 2043-2056. doi: 10.1016/j.jeurceramsoc.2011.04.036

Qu, B., Martin, A., Pastor, J. Y., Palomo, A., and Fernandez-Jimenez, A. (2016). Characterisation of pre-industrial hybrid cement and effect of pre-curing temperature. Cem. Concr. Compos. 73, 281-288. doi: $10.1016 /$ j.cemconcomp.2016.07.019

Rietveld, H. M. (1969). A profile refinement method for nuclear and magnetics structures. J. Appl. Crystallogr. 2, 65-71. doi: 10.1107/S0021889869006558

Ruiz-Santaquiteria, C., Skibsted, J., Fernández-Jiménez, A., and Palomo, A. (2013). Clay reactivity: production of alkali activated cements. Appl. Clay Sci. 73, 11-16. doi: 10.1016/j.clay.2012.10.012

Sánchez-Herrero, M. J., Fernández-Jiménez, A., and Palomo, A. (2012). Alkaline hydration of tricalcium aluminate. J. Am. Ceram. Soc. 95, 3317-3324. doi: 10.1111/j.1551-2916.2012.05348.x

Sánchez-Herrero, M. J., Fernández-Jiménez, A., and Palomo, A. (2016). Alkaline hydration of $\mathrm{C}_{2} \mathrm{~S}$ and $\mathrm{C}_{3}$ S. J. Am. Ceram. Soc. 99, 604-611. doi: $10.1111 /$ jace. 13985

Sánchez-Herrero, M. J., Fernández-Jiménez, A., and Palomo, A. (2017). $\mathrm{C}_{3} \mathrm{~S}$ and $\mathrm{C}_{2} \mathrm{~S}$ hydration in the presence of $\mathrm{Na}_{2} \mathrm{CO}_{3}$ and $\mathrm{Na}_{2} \mathrm{SO}_{4}$. J. Am. Ceram. Soc. 100 , 3188-3198. doi: 10.1111/jace.14855

Scrivener, K., Martirena, F., Bishnoi, S., and Maity, S. (2018b). Calcined clay limestone cements (LC3). Cem. Concr. Res. 114, 49-56. doi: 10.1016/j.cemconres.2017.08.017

Scrivener, K. L., Vanderley, M. J., and Gartner, E. M. (2018a). Eco-efficient cements: potential economically viable solutions for a low- $\mathrm{CO}_{2}$ cement-based materials industry. Cem. Concr. Res. 114, 2-26. doi: 10.1016/j.cemconres.2018.03.015

Shimada, Y., and Francis Young, J. (2004). Thermal stability of ettringite in alkaline solutions at $80^{\circ} \mathrm{C}$. Cem. Concr. Res. 34, 2261-2268. doi: 10.1016/j.cemconres.2004.04.008

Skibsted, J., and Andersen, M. D. (2013). The effect of alkali ions on the incorporation of aluminium in the calcium silicate hydrate (C-S-H) phase resulting from Portland cement hydration studied by ${ }^{29} \mathrm{Si}$ MAS NMR. J. Am. Ceram. Soc. 96, 651-656. doi: 10.1111/jace.12024

Staněk, T., and Sulovský, P. (2015). Active low-energy belite cement. Cem. Concr. Res. 68, 203-210. doi: 10.1016/j.cemconres.2014.11.004

Taylor, H. F. W. (1997). Cement Chemistry, 2nd Ed. London: ISBN

Vizcaíno-Andrés, L., Sánchez-Berriel, S., Damas-Carrera, S., Pérez-Hernández, A., Scrivener, K., and Fernando, M.-H. (2015). Industrial trial to produce a low clinker, low carbon cement. Mater. Constr. 65:e045. doi: 10.3989/mc.2015.00614

Wa, M., Zhang, Y., Ji, Y., Liu, G., Liu, C., She, W., et al. (2018). Reducing environmental impacts and carbon emissions: study of effects of superfine cement particles on blended cement containing high volume mineral admixtures. J. Clean. Product. 196, 358-369. doi: 10.1016/j.jclepro.2018.06.079

Zhang, T. S., Yu, Q. J., Wei, J. X., and Zhang, P. P. (2012). Efficient utilization of cementitious materials to produce sustainable blended cement. Cem. Concr. Compos. 34, 692-699. doi: 10.1016/j.cemconcomp.2012.02.004

Conflict of Interest Statement: The authors declare that the research was conducted in the absence of any commercial or financial relationships that could be construed as a potential conflict of interest.

Copyright (๑ 2019 Sánchez-Herrero, Fernández-Jiménez and Palomo. This is an open-access article distributed under the terms of the Creative Commons Attribution License (CC BY). The use, distribution or reproduction in other forums is permitted, provided the original author(s) and the copyright owner(s) are credited and that the original publication in this journal is cited, in accordance with accepted academic practice. No use, distribution or reproduction is permitted which does not comply with these terms. 